ENSAYO

\title{
LA RÚBRICA DE DON QUIJOTE (O PARA FIRMAR HAY QUE ESTAR LOCO)
}

\section{Cristóbal Alliende $\mathbf{P}$.}

En el capítulo XXV del Quijote de 1605 se encuentra un evento que la crítica cervantina ha pasado por alto. Don Quijote está con Sancho en Sierra Morena, a punto de hacer penitencia por su amada Dulcinea. Don Quijote redacta dos cartas, una dirigida a su imaginada señora, otra a su sobrina con el objeto de que ésta le entregue a su escudero unos pollinos. La primera carta lleva una firma previsible. Con la segunda surge un problema: Don Quijote no puede autentificar el mandato con su nombre, pues no tendría validez legal. Tampoco puede conceder abiertamente su identidad de hidalgo cincuentón de nombre Alonso Quijano. Sólo queda una solución: rubricar, no firmar, en el entendido de que uno y otro acto no eran lo mismo.

Para contextualizar e intentar demostrar la importancia que tiene la rúbrica que don Quijote estampa en Sierra Morena, en este trabajo se abordan también asuntos como el salario de Sancho y el episodio de la bacía o yelmo de Mambrino, más conocido como baciyelmo.

Cristóbal Alliende Piwonka. Ph.D. en literatura, Boston University. Actualmente es académico en la Universidad Adolfo Ibáñez y en la Universidad Alberto Hurtado. También es columnista estable del suplemento Artes y Letras del diario El Mercurio de Santiago.

Estudios Públicos, 100 (primavera 2005). 
Vencido por la realidad, por España, Don Quijote murió en su aldea natal hacia 1614. Poco tiempo lo sobrevivió Miguel de Cervantes.

Jorge Luis Borges, "Parábola de Cervantes y de Quijote".

\section{Introducción}

$\mathrm{E}$ Quijote de la Mancha aparece una clara crítica a la falta de verosimilitud de los libros de caballerías, asunto que será recurrente a lo largo de toda la obra. La crítica, hecha por el interlocutor y amigo del prologuista, representa una preocupación latente hacia principios del siglo XVII, y se ubica en el centro de la gigantesca máquina mal fundada de los libros de caballerías, libros que, al momento de nacer el Quijote, ya llevaban varias décadas en decadencia, en tanto que la picaresca, con obras como el Guzmán de Alfarache (1599), de Mateo Alemán, ganaba adeptos. Pero también existía conciencia de que no se trataba de un problema del género caballeresco, sino de su uso, especialmente en lo tocante a la plasmación textual de la realidad $^{1}$.

Una de las maneras que presenta el prólogo para superar las deficiencias de los libros de caballerías, es proponiendo un nuevo tipo de héroe, libre de artificios innecesarios y ajustado a la verdad, lo que se traduce en ésta, la "tan sincera y tan sin revueltas ... historia del famoso don Quijote de la Mancha, de quien hay opinión por todos los habitadores del campo de Montiel que fue el más casto enamorado y el más valiente caballero que de muchos años a esta parte se vio en aquellos contornos" (I, pp. 14$15)$.

Sin embargo, la impresión de verosimilitud en el prólogo, y en todo el Quijote, está siempre preñada de su contrario, de indeterminaciones y ambigüedades que ficcionalizan la historia. Demás está decir que inmediatamente después del prólogo de la Primera Parte, aparecen dedicatorias en honor a don Quijote: de la Celestina, del Lazarillo, de Orlando Furioso enloquecido, de Amadís y su escudero Gandalín, entre otros. Incluso aparece un diálogo metafísico entre dos caballos notables, Rocinante y Babieca. Los personajes ficticios que se dirigen a don Quijote no sólo convierten a éste en un componente más de la intención anticaballeresca general, sino además ridiculizan e invalidan cualquier componente aparecido en el prólogo que pueda haber sido tomado en serio.

${ }^{1}$ Con respecto a la recepción y crítica que los libros de caballerías tuvieron en tiempos de Cervantes, destaca el excelente estudio de Anthony Close The Romantic Approach to 'Don Quixote': A Critical History of the Romantic Tradition in 'Quixote' Criticism (Cambridge: Cambridge UP, 1978). 
A pesar de que desde el comienzo del Primer Capítulo se marcan diferencias importantes con los libros de caballerías, subsisten las indeterminaciones, verdaderas cortinas de humo que relativizan el proyecto original de rescatar el género en cuestión y terminar con sus desviaciones que, en rigor, son características que lo definen. "En un lugar de la Mancha, de cuyo nombre no quiero acordarme, no ha mucho tiempo que vivía un hidalgo . .." (I, I, p. 25). La Mancha es un espacio reconocible para el lector español del siglo XVII, una zona pobre y despoblada que poco tiene que ver con el exotismo fantástico de la tradicional novela caballeresca o con la lejanía que representan para el lector español los espacios ingleses o franceses. Otro tanto sucede con el "no ha mucho tiempo", que se distancia de los libros de caballerías, ya que éstos transcurrían en tiempos inmemoriales. Otro tanto sucede con la edad del don Quijote, 50 años, que contrasta con la juventud de un Esplandián o de un Amadís. También sobresale el uso del "don" del protagonista, práctica que debió haber causado cierta confusión e incluso risa en los lectores del siglo XVII, pues este título de dignidad podía ser usado sólo por los caballeros y los estratos sociales superiores a ellos, no por los hidalgos, que no eran más que un tipo de aristocracia baja con derechos mínimos ${ }^{2}$. De hecho, hacia fines del siglo XVI, la clase de los hidalgos ya había perdido su función guerrera ${ }^{3}$.

Lo interesante de esta permanente parodia de modelos preestablecidos, es que ella es a menudo ejecutada por quien la simboliza. Es decir, la misma parodia parece parodiar formas y figuras que ha aprendido con la lectura compulsiva de los libros de caballerías. Lo que permanece es la duda en cuanto al proceder de don Quijote: ¿el parodiado ejecuta su parodia consciente inconscientemente?

Este trabajo sólo se propone abordar esta última pregunta tangencialmente. La preocupación principal aquí es anterior a don Quijote o, más bien, envuelve a su origen y a los rastros que éste deja en el mundo imaginario del héroe. Porque en la base de don Quijote está su autobautizo, su capacidad casi ilimitada para nombrar y, con ella, transformar una realidad que no le sirve a su proyecto caballeresco.

${ }^{2}$ Hidalgo proviene de hijo de algo, que más tarde se simplificó en hi de algo.

${ }^{3}$ Hacia comienzos del siglo XVII, la clase de los hidalgos se encontraba de una situación curiosa, ampliamente conocida. Pertenecían oficialmente al último escalón de la aristocracia, por lo que, por lo general, no trabajaban; tenían alguna hacienda modesta y uno que otro lacayo. Como su función y roce social era mínimo, se caracterizaban por el ocio, el que en muchos casos derivaba en ocupaciones como la lectura. El surgimiento de la imprenta (mediados del siglo XV) les permitía a los hidalgos adquirir una pequeña biblioteca. Los libros de caballería fueron, hasta fines del siglo XVI, muy leídos por ellos y por todos los que habían perdido su rol guerrero. 
Primero, el héroe convierte a un famélico rucio en Rocinante, luego se transforma a sí mismo, de Alonso Quejana, Quesada o Quijano en don Quijote de la Mancha. Finalmente, nombra y crea a Dulcinea del Toboso, hasta entonces Aldonza Lorenzo (I, I, pp. 28-29). Cada uno de estos nombramientos lleva consigo la conciencia de un antes y de un después. Don Quijote se nombra a sí mismo y a los otros como un niño que maneja una fórmula mágica. Todo lo que tiene un caballero andante es creado a través de un cierto determinismo onomástico, un cambio de substancia.

Con respecto a la fundación de su propia persona, don Quijote rompe la jerarquía social de su momento para inventar otra que le es útil para su nueva y disparatada empresa. Y sin embargo, su nuevo nombre, al igual que el de Dulcinea, conserva un elemento cuerdo, toda vez que se estrella con la alcurnia que requieren un verdadero caballero andante y su amada. Los nombres Quijote y Dulcinea contrastan con los topónimos la Mancha y el Toboso, que refieren a lugares reconocibles, pobres y sin encanto.

"Yo sé quién soy" (I, V, p. 48), asegura don Quijote poco tiempo después de nombrarse a sí mismo e inaugurar oficialmente su proyecto. Pero ¿cuán loco está aquel que es capaz de articular abiertamente y dar respuesta a la pregunta que todos se hacen, los contemporáneos del hidalgo caballero y los lectores? Es decir, si el sujeto sabe quién es, entonces todo lo que hace a continuación cambia de sentido; toda controversia que aparece en el Quijote (temas ligados a la fe y la Iglesia, a la sociedad y su ordenamiento político, entre otros) vuelve a hacerse seria. Ya no se puede esgrimir tan fácilmente el argumento que indica que, como es don Quijote quien expone estos problemas y, claro, él está loco, entonces sus denuncias no tienen validez en el mundo de la razón. La locura de don Quijote ya no necesariamente lo absuelve de las querellas que provienen del mundo de Alonso Quijano ${ }^{4}$. Éste es el momento en el que esa locura queda preñada de su contrario ${ }^{5}$.

La crítica le ha destinado una enorme cantidad de esfuerzo al intento por desentrañar la naturaleza ambigua de don Quijote. Aún más grande es la bibliografía crítica existente en torno al asunto de la locura de nuestro héroe, estudios que van desde la aplicabilidad del psicoanálisis a su personali-

\footnotetext{
${ }^{4}$ En adelante me referiré a Alonso Quijano, pues éste es el nombre que él mismo (sumado a "el Bueno") se da momentos antes de morir (II, LXXIV, p. 487).

${ }^{5}$ No se debe olvidar que los desvaríos del héroe están relatados y comentados por fuentes difusas y poco creíbles. El autor-narrador-personaje de buena parte de la obra es el morisco Cide Hamete Benengeli y por ese entonces los moriscos eran considerados todos mentirosos, es decir, creadores de ficción. Además, en tiempos de Cervantes los moriscos en España eran un problema mayor y estaban a punto de ser expulsados. Y cabe recordar que Hamete significa "el que alaba" en tanto que Benengeli refiere a berenjena. Es el propio Sancho quien, más tarde, hace explícita la acepción jocosa (II, II, p. 27).
} 
dad, hasta aproximaciones erasmistas que darían cuenta de las lecturas que Cervantes habría querido aplicar en su escritura. Si bien estas interpretaciones sirven para explicar motivaciones generales y dar sentido a una fábula extraordinariamente ecléctica, lo que sigue en este trabajo se circunscribe a una marca, a un guiño que se lanza como al pasar y que bien puede servir para ubicar existencialmente a don Quijote.

Ese guiño tiene que ver con un problema práctico, un conflicto entre el ideal caballeresco y la resolución de menesteres sin los cuales la aventura en su conjunto queda en entredicho. Esa marca se ubica en el capítulo XXV de la Primera Parte del Quijote, cuando el protagonista y su escudero se encuentran en Sierra Morena, y refiere a la textualización y validación de identidades que poco antes habían sido cambiadas en su substancia a través del acto de nombrar: Me refiero a un breve episodio que convoca a la firma y la rúbrica; a su distinción, su vínculo con la identidad doble Alonso Quijano/don Quijote de la Mancha. En palabras modernas, y en el supuesto que el emisor ha perdido el juicio y se ha convertido en otra persona, ¿cómo se firma una carta para que sea considerada válida tanto para el mundo caballeresco de don Quijote como para el de ese viejo hidalgo de apellido Quijano que ha dejado de ser?

Antes de entrar a explicar este problema etimológico y semántico de la firma y la rúbrica y su importancia estructural a nivel de la configuración del personaje y su naturaleza ambigua, es necesario comprender cuál es el contexto en el que la mencionada marca es requerida. Sólo entonces se podrán aventurar ideas en torno al carácter fundacional del acto de nombrar, a la relevancia de lo que está ausente y a la identidad escindida del discreto don Quijote.

\section{Soluciones a problemas poco caballerescos}

Los primeros cincuenta años de don Quijote no existen. Los de Alonso Quijano los desconocemos. De Quijano no tenemos más que noticias esporádicas. A diferencia de don Quijote, Quijano nunca logra perfilarse como personaje, nunca logra superar o al menos acotar su calidad de actor. Casi se podría decir que Quijano no $e s^{6}$. Para la fábula, el pasado del hidalgo existe con el único objeto de dar pie para que se verifique la primera salida. En otras palabras, el narrador da a entender que lo digno de escribir-

${ }^{6}$ Basta remontarse a las primeras líneas del Quijote para comprobar la irrelevancia formal de Quijano. De hecho, no existe concordancia entre los "autores" de la obra respecto de si acaso era Quijano, Quijada o Quesada el apellido en cuestión, ante lo cual se concluye que "esto importa poco a nuestro cuento: basta que en la narración dél no se salga un punto de la verdad" (I, I, p. 26). 
se, lo posible de ser, es el conjunto de peripecias que involucran a la creación llamada don Quijote de la Mancha.

Sin embargo, por algún motivo, esos cincuenta años siguen estando presentes; se actualizan a través de silencios, meras sugerencias, iniciativas prácticas que presumiblemente son tributarias de situaciones aprendidas en ese tiempo. Es como si don Quijote nunca dejara de ser el hidalgo cincuentón que se pasó la vida leyendo libros de caballerías. De otro modo no se explica la manera en que don Quijote enfrenta ciertas situaciones que claramente superan el modelo caballeresco al que aspira. Es como si, inmerso como está en la lejana edad de oro, de pronto se viera forzado a actuar según los parámetros exigidos por la edad de hierro en que vive.

Existen algunos eventos que presagian y complementan esta capacidad de don Quijote para adaptarse a circunstancias que superan el esquema que sustenta su locura. En este primer capítulo destaco dos: El primero tiene que ver con el salario que recibe un escudero, en este caso Sancho Panza. El segundo ha sido ampliamente discutido por la crítica y refiere a la bacía o yelmo de Mambrino, más conocido como baciyelmo. Ambos eventos tienen como contraparte esa recurrente imagen de don Quijote atacando figuras que no son lo que dicen sus lecturas, figuras que, como él mismo asegura después de quedar mal herido, han sido trastocadas por algún tipo de Merlín.

\subsection{Los encantadores y la paga salarial}

Atrás quedó la primera salida y la necesidad del "recién nacido" don Quijote de nombrar todo lo que debe poseer un caballero andante, incluyéndose a sí mismo... Un "verdadero" caballero andante, equiparable e incluso superior a los doce Pares de Francia, por mucho que la investidura haya corrido por cuenta de un burlesco ventero.

Atrás ha quedado también ese "yo sé quién soy" (I, V, p. 48) que le imprime a la identidad de don Quijote / Alonso Quijano un grado de irresolución aún mayor. El lector no sabe a qué atenerse, pues, si su protagonista sabe quién es, todo lo que hace a continuación cambia de signo. Es la eterna pregunta por su grado de locura, por una posición que oscila entre la mentecatería absoluta y la discreción e incluso mesianismo más riguroso ${ }^{7}$. El procedimiento que avala la figura del héroe desquiciado es simple: Don Quijote sigue el guión preestablecido que le exige el modelo caballeresco

${ }^{7}$ Me refiero aquí a don Quijote como sujeto mesiánico en sentido erasmista: como alguien que lleva la fe cristiana más allá del rezo o de la mera observancia de los rituales eclesiásticos; es alguien que lleva dicha fe a la práctica, hasta sus últimas consecuencias. 
hasta que deja de funcionar, lo que impulsa su adaptación y la culpa de algún encantador que lo quiere mal. Más específicamente, el proceso, que involucra a Sancho Panza, es conocido: Don Quijote percibe algo del mundo exterior, para imponerle la visión de su imaginación. Sancho lo corrige. Don Quijote le responde a su escudero que él no está versado en esto de las aventuras caballerescas. Don Quijote se encomienda (a Dulcinea, a Dios, en este orden), ataca y choca. Sancho le hace ver a su amo que tenía razón. Don Quijote se justifica culpando al encantador de nombre Frestón o Fritón que lo quiere mal.

A partir de la segunda salida de don Quijote y su escudero este proceso se acentúa. Los molinos de viento han demostrado que el hidalgo no está del todo bien. Los narradores o encantadores / cronistas, hace varios capítulos que han sido convocados. Cide Hamete Benengeli se ha constituido en el historiador arábigo (mentiroso) que de tanto en tanto se ve sobrepasado narrativamente por un incierto "segundo autor" (I, VIII, p. 68) o editor de los cartapacios encontrados y luego mandados a traducir. Por entonces, don Quijote se ha fijado como ente de acción, como insólito sujeto que percibe algo del mundo exterior para luego imponerle la visión de su infinita imaginación. La explicación que sobre este proceder tienen quienes lo rodean, traducen y leen, es unívoco: don Quijote está loco.

En este contexto comienza a surgir un tema singular: el de la paga que deben recibir los escuderos. No hay nadie que sepa mejor que don Quijote que en los libros de caballerías no se hace referencia a asuntos prácticos como el salario. Sin embargo, don Quijote establece una paga para su escudero, la que incluye la promesa de entregarle una ínsula a medida que el héroe vaya ganando fama, promesa que efectivamente se cumple. El protagonista hace esto, justo antes y después de la aventura de los batanes, con una lucidez y pragmatismo inusitados. Don Quijote le asegura a Sancho que,

en lo que tocaba a la paga de sus servicios no tuviese pena, porque él había dejado hecho su testamento antes que saliera de su lugar, donde se hallaría gratificado de todo lo tocante a su salario, rata ${ }^{8}$ por cantidad, del tiempo que hubiese servido; pero que si Dios le sacaba de aquel peligro sano y salvo y sin cautela, se podía tener por muy más que cierta la prometida ínsula. (I, XX, p. 156.)

Poco más adelante, el proceder pragmático de don Quijote se extrema hasta el punto de situarse temporalmente alejado de los caballeros andantes y establecer el salario moderno:

${ }^{8}$ Prorrata, proporcionadamente. 
-No creo yo ... que jamás los tales escuderos estuvieron a salario, sino a merced; y si yo ahora te le he señalado a ti en el testamento cerrado que dejé en mi casa, fue por lo que podía suceder; que aún no sé cómo prueba en estos tan calamitosos tiempos nuestros la caballería, y no querría que por pocas cosas penase mi ánima en el otro mundo. Porque quiero que sepas, Sancho, que en él no hay estado más peligroso que el de los aventureros. (I, XX, p. 159.)

Este pasaje es muy significativo, puesto que contiene una serie de razonamientos que instalan a don Quijote en una suerte de posición panorámica: No sólo observa y elucubra sobre el mundo libresco que supuestamente lo ha desquiciado, sino que además observa y juzga el mundo temporal y espacial en el que efectivamente se mueve, cosa que ya había sugerido poco antes, al situar su nacimiento y al indicar que lo suyo es "resucitar" la edad de oro en ésta, la edad de hierro".

Aunque don Quijote no ha leído que los escuderos hayan trabajado para sus amos a merced, él supone que en aquellos tiempos dorados no podían hacerlo a sueldo. Al menos, el salario no cabía, ni siquiera hipotéticamente, en ninguno de los referentes literarios que el héroe adoptó como propios (fundamentalmente los modelos caballeresco y pastoril). Don Quijote también es capaz de referir al testamento en términos modernos, no caballerescos, por cuanto contiene provisiones pecuniarias que favorecen a su escudero por los servicios prestados. Ello, ante la inseguridad de que la caballería andante pueda tener cabida en estos "calamitosos tiempos". Éste es un ejercicio consciente de transmutación por parte de don Quijote, de su realidad post-caballeresca y amenazante en materia libresca.

El tema del trabajo de escudero y de su salario será un verdadero leitmotiv del Quijote de 1615, en donde don Quijote fija un sueldo justo para su escudero, con lo que sienta un precedente. La actualización o modernización del modelo caballeresco hasta el establecimiento de una paga para Sancho se realiza de acuerdo a parámetros absolutamente racionales. Un escudero trabaja y arriesga más que un sirviente de un labrador. Y como Sancho tenía ese oficio antes de convertirse en escudero, el cálculo es relativamente fácil. Don Quijote acepta el monto a pagar y, con ello, mantiene el equilibrio entre su empresa y los requerimientos que a ella le exigen el tiempo y el espacio en los que se desarrolla:

9 "Yo nací, por querer del cielo, en esta nuestra edad de hierro, para resucitar en ella la de oro, o la dorada, como suele llamarse. Yo soy aquel para quien están guardados los peligros, las grandes hazañas, los valerosos hechos. Yo soy . . quien ha de resucitar los de la Tabla Redonda, los Doce Pares de Francia, y los Nueve de la Fama ..." (I, XX, p. 149). 
- Cuando yo servía - [dijo] Sancho- a Tomé Carrasco, el padre del bachiller Sansón Carrasco, que vuestra merced bien conoce, dos ducados ganaba cada mes, amén de la comida; con vuestra merced no sé lo que puedo ganar, puesto que sé que tiene más trabajo el escudero del caballero andante que el que sirve a un labrador...

- Confieso - dijo don Quijote- que todo lo que dices, Sancho, sea verdad. ¿Cuánto parece que os debo dar más de lo que os daba Tomé Carrasco?

-A mi parecer — dijo Sancho-, con dos reales más que vuestra merced añadiese cada mes me tendría por bien pagado ...

—Está muy bien — replicó don Quijote-; y conforme al salario que vos os habéis señalado, veinticinco días ha que salimos de nuestro pueblo: contad, Sancho, rata por cantidad, y mirad lo que os debo, y pagaos, como os tengo dicho, de vuestra mano. (II, XXVIII, pp. 201-202.)

La promesa de don Quijote no sólo se cumple, sino que ella es adoptada por Alonso Quijano el Bueno en su lecho de muerte, al finalizar el Quijote de 1615. Es decir, a pesar de que el moribundo hidalgo reniega de su pasado inmediato como caballero andante y lo califica de locura, él acepta y considera justo mantener el salario acordado entre Sancho y don Quijote (II, LXXIV, p. 488).

Este tipo de liberalidad en don Quijote en cuanto a aceptar la incorporación de elementos nuevos, provenientes de los "calamitosos tiempos" de la edad de hierro, funciona bien en situaciones que carecen de precedente libresco. Sin embargo, existen otras situaciones, más circunscritas, físicas y antagónicas, en las que don Quijote se ve obligado a recurrir a estrategias más sutiles, estrategias que deben mantener las propiedades de las concepciones de mundo en disputa.

\subsection{La solución baciyélmica}

La aventura de los batanes y las singulares menciones al tema del salario que le corresponde a Sancho como escudero, sirven para introducir la siguiente aventura del yelmo de Mambrino (I, XXI, pp. 159-170). Esta aventura puede leerse como un primer intento por parte del protagonista por solucionar asuntos teóricos y prácticos que enfrenta su empresa, aunque su verbalización ocurre bastante después y la ejecuta Sancho Panza.

Nos encontramos en momentos en que el engaño producido por la aventura de los batanes ha sido reconocida por don Quijote. Esta acepta- ción no lo inhibe de continuar inmediatamente aplicando su cosmovisión caballeresca: Al ver que se aproxima un humilde hombre a caballo que, según el propio narrador, "traía en la cabeza una cosa que relumbraba como 
si fuera de oro" (I, XXI, p. 160), don Quijote no duda en convertir al sujeto que se acerca en el objeto de un nuevo lance que superará el golpe recibido en el anterior: "Paréceme, Sancho, que no hay refrán que no sea verdadero, porque todos son sentencias sacadas de la mesma experiencia, madre de las ciencias todas, especialmente aquel que dice: 'Donde una puerta se cierra, otra se abre"" (I, XXI, p. 160).

Don Quijote lo que ve es un imponente caballero sobre un "caballo rucio rodado, que trae puesto un yelmo de oro" (I, XXI, p. 161). Sancho, en cambio, ve "un hombre sobre un asno, pardo como el mío, que trae sobre la cabeza una cosa que relumbra" (I, XXI, p. 161). Don Quijote mantiene su postura y agrega que aquello que brilla es el yelmo de Mambrino. El narrador hace aquí una aclaración, toma partido ante el equívoco de don Quijote: Explica el origen del barbero, cuenta que va de un pueblo a otro, montando en efecto un asno pardo; este barbero trae una bacía de azófar en la cabeza para que su sombrero no se estropee, pues poco antes había comenzado a llover. Y remata el narrador aludiendo a don Quijote: "que todas las cosas que veía con mucha facilidad las acomodaba a sus desvariadas caballerías y malandantes pensamientos" (I, XXI, p. 161).

Don Quijote ataca al pobre hombre, quien escapa despavorido, dejando atrás la bacía. Sancho la recoge, se la da a su amo, y éste se la prueba en la cabeza sin éxito, ante lo cual exclama: "Sin duda que el pagano a cuya medida se forjó primero esta famosa celada debía de tener grandísima cabeza; y lo peor de ello es que le falta la mitad." Sancho no puede contener la risa, al imaginar "la gran cabeza que tenía el pagano dueño de este almete, que no semeja sino una bacía de barbero pintiparada" (I, XXI, p. 162).

La alusión del narrador al "acomodo" del caballero andante es fundamental. Don Quijote no ve lo que no existe, sino que adapta el objeto hasta cambiarle su identidad. La suya es una postura intermedia, que intenta equilibrar su versión con las de Sancho y del narrador. A diferencia de lo que sucede en aventuras anteriores, esta vez don Quijote desecha la posibilidad de arremeter contra la realidad y mantener su postura inflexible. El gesto de probarse la bacía lo obliga a adaptar su impresión inicial, hasta el punto de mediar entre las visiones del otro y la suya:

- ¿Sabes qué imagino, Sancho? Que esta famosa pieza de este encantado yelmo por algún extraño accidente debió de venir a manos de quien no supo conocer ni estimar su valor, $y$, sin saber lo que hacía, viéndola de oro purísimo, debió de fundir la otra mitad para aprovecharse del precio, y de la otra mitad hizo esta que parece bacía de barbero, como tú dices. Pero sea lo que fuere; que para mí que la conozco no hace al caso su transmutación. (I, XXI, p. 162.) 
La solución termina con la risa de Sancho y vincula dos ámbitos que hasta hace poco se mostraban incompatibles. El yelmo se ha convertido en bacía, aunque su esencia — digamos, yélmica - permanece intacta. Existe en don Quijote conciencia de un devenir en el que el objeto, "por algún extraño acidente", fue ignorado, aunque no su valor, pues se mantiene la idea de que está hecho de oro purísimo. Y la "transmutación" no tiene importancia, porque don Quijote posee un saber inobjetable: él conoce desde hace mucho tiempo el yelmo de Mambrino.

La de don Quijote es una especie de postura platónica, en cuanto todos los objetos que ve son un pálido reflejo de la realidad superior que los sustenta. Don Quijote, entonces, intenta ir más allá de lo aparente, lo que redunda, para Sancho, para el narrador y para el lector implícito, en la imposibilidad de sacarlo de su locura o de los márgenes que le impone la lectura de los libros de caballerías. Y si esta lectura no cubre algún aspecto de sus aventuras, don Quijote hace lo mismo que hizo con el salario de Sancho, esto es, actualizar el modelo.

Un ejemplo del vacío que, con respecto a asuntos prácticos, contiene el género caballeresco, ocurre inmediatamente después de la huida del barbero ante el ataque del caballero andante. El barbero ha abandonado a su rucio, ante lo cual Sancho se pregunta si acaso puede quedárselo o, al menos, cambiarlo por el suyo. Su amo responde que "nunca yo acostumbro ... despojar a los que venzo, ni es uso de caballería quitarles los caballos y dejarlos a pie" (I, XXI, p. 164), a menos que el vencedor haya perdido su animal. Entonces, Sancho plantea la posibilidad de, al menos, intercambiar los aparejos de su rucio por los del abandonado. Un detalle mínimo como éste no puede ser solucionado por las novelas de caballerías, por lo que don Quijote se ve obligado, una vez más, a sentar precedente: "En eso no estoy muy cierto ... y en caso de duda, hasta mejor estar informado, digo que los trueques, si es que tienes dellos necesidad extrema" (I, XXI, p. 164).

Bastante más adelante, en el capítulo XLIV, don Quijote y su escudero vuelven a encontrarse con el barbero, esta vez en la venta-castillo de Palomeque. El barbero reconoce a Sancho, lo increpa y ataca. Sancho se defiende como puede ante la arremetida. Acuden todos los que están en la venta y escuchan los descargos del recién venido, quien asegura que Sancho y su amo le han robado su albarda y su bacía. Don Quijote interviene, asegurando que los objetos fueron ganados por él en justa batalla y que lo que parece albarda es en realidad jaez. Estas transformaciones, prosigue don Quijote, son comunes en el mundo de la caballería, y, para probarlo, manda a Sancho a buscar "el yelmo que este buen hombre dice ser bacía" (I, XLIV, p. 406). A continuación, se inicia este famoso diálogo, frente a todos los que se encuentran en la venta, quienes actúan como jueces: 
—Pardiez, señor — dijo Sancho-, si no tenemos otra prueba de nuestra intención que la que vuestra merced dice, tan bacía es el yelmo de Malino como el jaez deste buen hombre albarda.

- Haz lo que te mando — replicó don Quijote-; que no todas las cosas deste castillo han de ser guiadas por encantamento. (I, XLIV, p. 406.)

Don Quijote toma en sus manos la bacía y exclama:

- Miren vuestras mercedes con qué cara podía decir este escudero que ésta es bacía, y no el yelmo que yo he dicho; y juro por la orden de caballería que profeso que este yelmo fue el mismo que yo le quité, sin haber añadido en él ni quitado cosa alguna.

-En eso no hay duda — dijo a esta sazón Sancho-; porque desde que mi señor le ganó hasta agora no ha hecho con él más de una batalla, cuando libró a los sin ventura encadenados; y si no fuera por este baciyelmo, no lo pasara entonces muy bien, porque hubo asaz de pedradas en aquel trance. (I, XLIV, p. 406.)

El vínculo entre los molinos y los gigantes es restablecido, ahora con el binomio yelmo-bacía. Don Quijote se mueve con el mismo convencimiento que en la tradicional aventura, pero algo más cauteloso y abierto a intentar convencer a quienes lo rodean de la veracidad de su versión.

Ésta es una disputa que comienza a desarrollarse en el plano de las ideas y, más específicamente, a nivel de las palabras. El choque entre la realidad percibida por don Quijote y la de quienes lo rodean es esta vez epistemológico, pero el resultado es el mismo, pues su prueba, que sostiene en sus manos, lo incrimina. Sin embargo, Sancho adopta y da el nombre de "baciyelmo" a la alternativa que ya había sugerido su amo al intentar explicar las excesivas dimensiones del supuesto yelmo. El escudero no sólo bautiza al objeto en disputa como baciyelmo, sino además da un argumento para ello: los objetos se distinguen o identifican por su uso, y puesto que éste en particular sirvió en una aventura reciente para proteger la cabeza de su amo de las pedradas lanzadas por los galeotes, entonces no cabe duda que merece llevar el nombre de yelmo, aunque su apariencia indique que es bacía $^{10}$.

${ }^{10}$ En el capítulo XXII don Quijote libra una de las pocas batallas en las que sale victorioso y que no requieren de soluciones que avalen la acción. Es la liberación de los galeotes - entre los que se encuentra Ginés de Pasamonte-, en donde aflora el buen juicio del héroe y una de las tantas críticas al sistema judicial imperante. Tanto su discurso sobre el libre albedrío (I, XXII, p. 174) como su visión de la justicia (I, XXII, pp. 176177), son destacables, pues refieren al tiempo y espacio de Alonso Quijano, y no a los de 
En el citado pasaje del final del capítulo XLIV, al comenzar a cerrarse el Quijote de 1605, Sancho funda oficialmente la filosofía baciyélmica. "Baciyelmo" es un neologismo que soluciona un problema puntual: hace compatibles la agresión y robo sufrido por el barbero, con la convicción de don Quijote de haber ganado una batalla y obtenido en ésta un botín en buena ley. Sobre todo, la creación del baciyelmo hace compatibles y resume soluciones ingeniosas pero puntuales de una aventura. Cada uno de los integrantes de antítesis fundamentales que llevan en sí el Quijote y su héroe, como cordura / locura, heroísmo / necedad, ficción / realidad, armas / letras, fe / obras, entre otros, parecen siempre caer pesadamente a tierra para luego levantarse y continuar indefinidamente con sus querellas, al igual que ciertas acciones de don Quijote que se han hecho emblemáticas. En este contexto, la figura del baciyelmo le ha servido a la crítica para identificar un singular intento cervantino de conciliación entre los opuestos, una fórmula que permite denunciar asuntos delicados, sin que ello derive en un desafío abierto a la autoridad.

El mismo episodio del baciyelmo sirve para introducir el capítulo XLV y su tema fundamental: el que hace manifiesta, una vez más, la distorsión de la realidad que sufre don Quijote, pero esta vez desde un ángulo inverso, esto es, desde el punto de mira del héroe: Ahora es el mismo caballero andante quien se encarga de explicar las consecuencias de los frecuentes encantamientos que sufre; ahora acepta como posible que sea él, y no los que lo juzgan, quien tiene afectado su aparato de percepción, con lo que, conscientemente, se coloca en una esfera distinta. Dirigiéndose a todos quienes se encuentran en la venta, dice don Quijote:

quizá por no ser armados caballeros como yo lo soy no tendrán que ver con vuestras mercedes los encantamentos de este lugar, y tendrán los entendimientos libres, y podrán juzgar de las cosas de este castillo como ellas son real y verdaderamente, y no como a mí me parecían. (I, XLV, p. 408.)

Así, la realidad es entendida como manifestación de la mayoría, como una versión probable que, como sucede luego, puede ser trastocada. Ante el desacuerdo que suscita la albarda / jaez, la venta se transforma en un campo de batalla. Paradójicamente, en este caos de gritos, puñetazos y

los libros de caballerías. Sin embargo, y como suele suceder en momentos en que don Quijote parece adoptar una actitud unívoca con respecto a algún incidente que lo involucra directamente, el héroe deshace todo lo avanzado e inserta una acción o idea que lo vuelve a convertir en loco. En este caso, a continuación de la liberación de los galeotes les pide a éstos que se presenten "ante la señora Dulcinea del Toboso, y le digáis que su caballero el de la Triste Figura se le envía a encomendar" (I, XXII, p. 178). 
palos, es don Quijote, el loco, quien se erige como el único que pone una nota cuerda, hasta el punto de detener la trifulca por medio de un discurso propio de la figura del líder racional:

-Ténganse todos; todos envainen; todos se sosieguen; óiganme todos, si todos quieren quedar con vida . . Mirad cómo allí se pelea por la espada, aquí por el caballo, acullá por el águila, acá por el yelmo, y todos peleamos, y todos no nos entendemos. Venga, pues, vuestra merced, señor Oidor, y vuestra merced, señor Cura, y el uno sirva de rey Agramante, y el otro de rey Sobrino, y póngannos en paz; porque por Dios Todopoderoso que es gran bellaquería que tanta gente principal como aquí estamos se mate por causas tan livianas. (I, XLV, p. 410.)

Don Quijote ha sabido adaptar su mentalidad caballeresca y aplicarla, con éxito, a los requerimientos prácticos que demandan situaciones y personajes que sólo aceptan a Alonso Quijano. Además, la reversibilidad inherente a la filosofía baciyélmica queda confirmada, cosa que se repite en los capítulos XLVI y XLVII: Don Quijote vuelve rápidamente a su condición de loco, la que lo salva de ser apresado como salteador de caminos por la Santa Hermandad, pues, como dice el Cura, los delitos cometidos por un sujeto como éste no son punibles (I, XLVI, p. 414) ${ }^{11}$.

Si bien el baciyelmo es la primera fijación verbal manifiesta del intento de conciliación de opuestos presentes en el Quijote, hay otra fijación anterior sobre la cual la crítica no ha reparado y que, a pesar de aparecer implícita, tiene consecuencias que incluso superan el acierto de Sancho. Se trata de una solución propuesta por el propio don Quijote para salvar la convivencia de sus identidades actual y pasada y de sus textualizaciones o sellos legales: su firma y su rúbrica.

\section{Para firmar hay que estar loco}

Al llegar a Sierra Morena (I, XXIII), don Quijote hace varios días que ha dejado de ser el hidalgo Alonso Quijano. Ya se han desarrollado, por separado, los temas caballeresco y amoroso, los que se condensan en trece capítulos y cinco aventuras (la de los rebaños, del cuerpo muerto, de los

${ }^{11}$ La reversibilidad baciyélmica es aplicable no sólo a don Quijote. También sirve para describir acciones como las del Cura Pero Pérez. Recordemos que éste, para lograr su objetivo de hacer que Alonso Quijano vuelva a su casa —objetivo sobre el cual gira buena parte del Quijote de 1605-, el Cura, que hasta entonces simbolizaba la cordura, no duda en convertirse en encantador, hasta el punto de dirigir la representación de una obra fantástica creada por él mismo: "La invención de la libertad de la reina Micomicona" (I, XLVI, pp. 413-420). 
batanes, del yelmo de Mambrino y la de los Galeotes), además de la penitencia que don Quijote decide hacer en dicha sierra ${ }^{12}$.

Al llegar a Sierra Morena, don Quijote ha dejado entrever que hay situaciones límite que no ameritan un enfrentamiento y desenlace brutales (choque contra molinos) ni explicaciones inobjetables (rol de encantadores o fabuladores que lo quieren mal). Son situaciones que, como el caso de la bacía de barbero / yelmo de Mambrino, adquieren, por influjo de don Quijote, características que les son hasta ese momento desconocidas. Como está dicho, se trata de los temas de la interpretación y de la capacidad de don Quijote para adaptar y explicar - y ya no sólo rechazar o atacar frontalmente- las cosas que lo rodean de acuerdo con su particular teoría y capacidad resolutiva, teoría y capacidad que encuentran en Sierra Morena su máxima expresión.

Don Quijote se halla en Sierra Morena imitando la penitencia que Amadís hizo en la Peña Pobre ${ }^{13}$. Sancho se mofa del nuevo afán de su amo, ante lo cual éste responde: "quiérote hacer sabidor de que todas estas cosas que hago no son burlas, sino muy de veras" (I, XXV, p. 206). Es tan serio don Quijote en su empresa de imitar a Amadís y sus penas de amores, que extrema su celo por seguir exactamente el procedimiento penitencial, hasta el punto de cumplir con el requisito imprescindible de enviarle, por intermedio de su escudero, una carta de despecho a su amada. Las pocas ganas que Sancho tiene de cumplir su rol de estafeta quedan superadas una vez que don Quijote acepta que el encargo sirva también para que el escudero reciba, de manos de la sobrina Antonia Quijana, unos pollinos que le tenía prometido, para lo cual se redacta una segunda carta con su respectiva "libranza pollinesca" (I, XXV, p. 207), escrita ésta en el reverso de la primera, todo en una de las hojas del librillo de memoria que perteneció a Cardenio.

Al discutir la necesidad de que el escudero oficie de emisario y de que el texto sea trascrito por algún escribano, surge este diálogo:

${ }^{12}$ Sigo aquí el esquema propuesto por Joaquín Casalduero en Sentido y forma del Quijote (Madrid: Ínsula, 1966).

${ }^{13}$ A diferencia de la de Amadís, la de don Quijote es una locura de amores "en seco", pues Dulcinea mal podría haber dado pie para lo contrario:

"-Paréceme a mí - dijo Sancho- que los caballeros que lo tal ficieron fueron provocados y tuvieron causa para hacer esas necedades y penitencias; pero vuestra merced, ¿qué causa tiene para volverse loco? ¿Qué dama le ha desdeñado, o qué señales ha halado que le den a entender que la señora Dulcinea del Toboso ha hecho alguna niñería con moro o cristiano?

- Ahí está el punto — respondió don Quijote-y ésa es la fineza de mi negocio; que volverse loco o caballero andante con causa, ni grado ni gracias: el toque está desatinar sin ocasión y dar a entender a mi dama que si en seco hago esto, ¿qué hiciera en mojado?” (I, XXV, pp. 202-203). 
-Pues ¿qué se ha de hacer de la firma? - dijo Sancho.

-Nunca las cartas de Amadís se firman — respondió don Quijote.

-Está bien — respondió Sancho-; pero la libranza forzosamente se ha de firmar, y ésa si se traslada, dirán que la firma es falsa, y quedaréme sin pollinos.

- La libranza irá en el mesmo librillo firmada; que en viéndola mi sobrina, no pondrá dificultad en cumplilla. (I, XXV, p. 207.)

Luego se entenderá que no basta con la firma única que oficializa al librillo y sus contenidos dispares. Poco más abajo, al escribir las cartas de amor a la imaginada Dulcinea y de petición de entrega de salario a la sobrina, el asunto de la validación del emisor se complica y pone a don Quijote en una situación que desafía, una vez más, su identidad de caballero andante o, más bien, de penitente. La diferencia radica en que esta vez el héroe se ve forzado a inventar una radical solución baciyélmica a las obligaciones diversas que le exigen los mundos inmediato e imaginado.

En medio de este dilema que comienza a configurarse y a adquirir proporciones importantes, en el siguiente diálogo con su escudero don Quijote concede una serie de características acerca de Dulcinea, incluyendo su verdadera identidad:

... a lo que yo me sé acordar, Dulcinea no sabe escribir ni leer, y en toda su vida ha visto letra mía ni carta mía, porque mis amores y los suyos han sido siempre platónicos, sin extenderse a más que un honesto mirar ... [T]al es el recato y el encerramiento con que su padre Lorenzo Corchuelo y su madre Aldonza Nogales la han criado.

— ¡Ta, ta! — dijo Sancho-. ¿Que la hija de Lorenzo Corchuelo es la señora Dulcinea del Toboso, llamada por nombre Aldonza Lorenzo?

-Ésa es —dijo don Quijote-, y es la que merece ser señora de todo el universo. (I, XXV, p. 208.)

Ésta es una aceptación explícita por parte de don Quijote de la invención de Dulcinea o, al menos, de la idealización consciente de una mujer común (Aldonza Lorenzo) por otra imaginada (Dulcinea del Toboso). Con este gesto, casi se podría decir que con el citado diálogo don Quijote comienza a admitir que su propia identidad es un constructo racional, meditado y alejado de la locura que le achacan muchos de los que lo rodean.

Dice la carta de don Quijote a Dulcinea del Toboso:

Soberana y alta señora:

El ferido de punta de ausencia y el llagado de las telas del corazón, dulcísima Dulcinea del Toboso, te envía la salud que 
él no tiene. Si tu fermosura me desprecia, si tu valor no es en mi pro, si tus desdenes son en mi afincamiento, maguer que yo sea asaz de sufrido, mal podré sostenerme en esta cuita, que, además de ser fuerte, es muy duradera. Mi buen escudero Sancho te dará entera relación ¡oh bella ingrata, amada enemiga mía! del modo que por tu causa quedo; si gustares de acorrerme, tuyo soy; y si no, haz lo que te viniere en gusto; que con acabar mi vida habré satisfecho a tu crueldad y a mi deseo.

Tuyo hasta la muerte,

El Caballero de la Triste Figura. (I, XXV, pp. 210-211.)

Dice la carta a la sobrina escrita en el reverso de la misiva anterior:

Mandará vuestra merced, por esta primera de pollinos, señora sobrina, dar a Sancho Panza, mi escudero, tres de los cinco que dejé en casa y están a cargo de vuestra merced. Los cuales tres pollinos se los mando librar y pagar por otros tantos aquí recebidos de contado; que con ésta y con su carta de pago serán bien dados. Fecha en las entrañas de Sierra Morena, a veinte y dos de Agosto deste presente año. (I, XXV, p. 211.)

El cambio de estilo es evidente. La primera es una epístola sentimental llena de fórmulas literarias. La segunda es un mandato. Más importante aún, a diferencia de la misiva amorosa, el segundo texto no lo cierra el "Caballero de la Triste Figura" ni ninguna otra marca, cosa que es advertida por Sancho. Para el escudero, la petición formal a la sobrina debe ser firmada al igual que la carta destinada a Dulcinea, con lo que se descarta la posibilidad de que el conjunto o librillo pueda ser validado por medio de una sola firma. Éste es el momento notable en que don Quijote encuentra una alternativa que le permite mantener su proyecto caballeresco.

—Buena está — dijo Sancho [refiriéndose a la carta a la sobrina]_: fírmela vuestra merced.

—No es menester firmarla - dijo don Quijote-, sino solamente poner mi rúbrica, que es lo mesmo que firma, y para tres asnos, y aun para trecientos, fuera bastante. (I, XXV, p. 211.)

Evidentemente, a diferencia de la dirigida a Dulcinea, "El Caballero de la Triste Figura" no puede aparecer autentificando el mandato. Tampoco "Don Quijote de la Mancha". Ambas firmas no tienen ningún valor práctico o aceptable para los parámetros que maneja Antonia Quijana, sobrina de Alonso Quijano... ¿Y quién nos da a entender este problema? El propio don Quijote, el loco... ¿O es Alonso Quijano, el cuerdo? 
Rúbrica y firma tuvieron hasta hace no mucho significados diferentes. Complementarios, pero diferentes. Como está dicho, descubrir lo que implican una y otra, lejos de simplemente ayudar a entender el pasaje en cuestión, lo singulariza y complica de manera inusitada.

\subsection{Etimologías y significados}

Tanto la firma como la rúbrica están vinculadas, desde el punto de vista del contenido, a múltiples acepciones. Aquí me ocupo sólo de aquellas aplicables al contexto del recién citado diálogo entre don Quijote y su escudero ${ }^{14}$.

Desde un punto de vista etimológico, firma es un derivado del latín vulgar FIRMIS, luego FIRMUS, en español, firme ${ }^{15}$.

El Diccionario de la Lengua Española de la Real Academia, en tanto, señala:

FIRMA (De firmar). f. Nombre y apellido, o título, de una persona, que ésta pone con rúbrica al pie de un documento escrito de mano propia o ajena, para darle autenticidad o para obligarse a lo que en él se dice. // 2. Nombre y apellido, o título, de la persona que no usa rúbrica, o no debe usarla, puesto al pie de un documento (p. 644.)

En cuanto a la rúbrica, etimológicamente deriva del latín RUBEUS ("rojizo"), hoy rubio, y se encuentra ya como voz castellana en diferentes textos (entre ellos el Quijote) desde comienzos del siglo XVI (Corominas, V, p. 81).

Dice el Diccionario de la Lengua Española:

RÚBRICA. (Del lat. rubrica). f. desus. Señal encarnada o roja. // 2. Rasgo o conjunto de rasgos de figura determinada, que como parte de la firma pone cada cual después de su nombre o título. A veces pónese la sola; esto es, sin que vaya precedida del nombre o título de la persona que rubrica (p. 1202.)

Es notable que en la edición de Autoridades (1726-1739), la distinción entre rúbrica y firma está ejemplificada, precisamente, por el pasaje citado de la esquela de don Quijote a su sobrina. Asimismo, este diccionario

${ }^{14}$ Además de la acepción aquí elegida, la rúbrica también remite, por ejemplo, a la función de designar las reglas que enseñan la práctica de las ceremonias y ritos de la Iglesia en los Oficios divinos y funciones religiosas.

${ }^{15}$ Como aparece en Corominas, la primera noticia que se tiene del lexema firma data de la segunda mitad del siglo X, en las Glosas de Silos (II, p. 902). 
entiende por el verbo rubricar el "subscribir, firmar y sellar algún despacho o papel, con el sello o escudo de armas de aquel en cuyo nombre se escribe: que por estamparle sobre oblea o lacre, que son de color rubro o encarnado, se pudo decir Rubricar" (pp. 648-649).

Así, rúbrica, en su sentido original y en uso pleno durante los siglos XV, XVI y XVII, remite a un rasgo o símbolo personal ("e intransferible", diríamos hoy) que acompaña al significante inteligible del sujeto que escri$b^{16}$. La firma, en cuanto "nombre o título de la persona que rubrica", requiere de un signo que la individualice, que permita validar con aun mayor certeza la autenticidad del documento ${ }^{17}$. El conjunto (firma más rúbrica) adquiere, entonces, características únicas y reconocibles para todo destinatario que conoce de antemano esta marca.

Rúbrica y firma, en suma, se fueron con el tiempo confundiendo hasta el punto que en la actualidad funcionan como sinónimos ${ }^{18}$. Lo que sí persiste del conjunto es el carácter de contraseña inobjetable, de marca que certifica la identidad del sujeto y la autenticidad del texto que la precede.

\section{La brillante solución quijotesca}

Se ha señalado que existe un antes y un después del bautizo por parte de don Quijote - y de Rocinante, de Dulcinea y de otros sujetos y objetos que de pronto comienzan a equilibrarse entre dos identidades: la vieja, conocida, cuerda, y la advenediza, extranjera, loca, quijotesca. Este gesto de don Quijote de nombrar o volver a bautizar sujetos y objetos, implica una suerte de cambio de substancia, de determinismo onomástico que funda lo que sólo esporádicamente, por intermedio de guiños hechos como al pasar, será puesto en relieve. Se trata del carácter fundador del hecho de nombrar.

También se ha sugerido que existe una especie de hiato, de velo que cubre un pasado que, por algún motivo, no ha de ser conocido por el

${ }^{16}$ Apunta Covarrubias: "[Rúbrica es] la inscripción de los títulos del derecho. Díxose assí porque se escrive con letra colorada para diferenciarse de la demás escritura" (1993, p. 916).

${ }^{17}$ Diversas fuentes tienden a coincidir en cuanto a que hacia el siglo XVI la relación entre firma y rúbrica estaba bien delimitada. Particularmente clara es la Enciclopedia universal ilustrada. Con respecto a la rúbrica, dice: "Rasgo o sistema de rasgos que suelen seguir a las letras de la firma para dar a ésta un sello más personal y característico. No es la rúbrica requisito esencial de la firma; y así, de la misma manera que a veces se encuentra desprovista de aquélla, en ocasiones la rúbrica se estampa sola, como, por ejemplo, en las providencias del sumario dictadas por el juez de instrucción” (LII, p. 648).

${ }^{18}$ A diferencia de la acepción antigua, la inteligibilidad de la firma hoy por hoy no es necesaria. 
receptor. Es, por ejemplo, lo no-dicho respecto a los mencionados cincuenta años de Alonso Quijano. Pero sabemos que las elipsis, al ser negadas explícitamente o al ser textualizadas, pierden parte de su propiedad; lo no-dicho, al ser identificado y verbalizado como "no-dicho" se llena de sentido y, aunque su contenido original permanece velado, los lectores ya nos encontramos en una posición que nos permite deducir lo que hasta hace poco no sólo desconocíamos, sino que ignorábamos que desconocíamos.

Esos espacios inéditos que en el Quijote se nos aparecen a través de su velo, son los que parte de la crítica ha identificado como lo "otro". Es lo "otro", lo que no aparece en el texto pero que sabemos está allí, lo que nos impulsa a entender a don Quijote como un sujeto que hace y piensa cosas que, al no estar inscritas en la obra que lo enmarca, le otorgan propiedades insospechadas. Estas propiedades dieron pie para que Michel Foucault entendiera a don Quijote como un "alienado en la analogía", como alguien que deambula o juega "en serio" entre lo Mismo y lo Otro (Cruz, 1984, pp. 93116).

Don Quijote no encuentra necesario firmar. Dice que con la rúbrica basta para darle validez al documento que beneficia a Sancho. Don Quijote escribe esa marca distintiva, pero no tenemos acceso directo a ella. Los lectores sabemos que la firma dice "El Caballero de la Triste Figura", sin embargo desconocemos qué dice o simboliza la rúbrica. Está ahí implícita en la fábula, ella es lo "otro" que envuelve y distingue al héroe. Sí sabemos una cosa: esa marca que va al pie de la carta dirigida a Antonia Quijana debe representar dos identidades que se contraponen.

\subsection{Lo mismo: Nombre(s), atisbo(s) de identidad}

Sabemos que ser hidalgo significaba pertenecer a la baja aristocracia. Era, por así decirlo, el último escalón de la clase privilegiada. Aun así, persistían diferencias importantes entre los hidalgos y la plebe. Entre ellas, muy probablemente un pasado algo más venturoso, de escudos de armas, de haciendas más señoriales que las existentes en tiempos de Cervantes y don Quijote e influencias relativamente directas en la corte. Con el tiempo, estos privilegios tendieron a desaparecer, mas no del todo. La pertenencia a la nobleza, aunque sea en su mínima expresión, bien podía redundar en marcas que así lo aseguraban. Es lo que presumiblemente sucede con el hidalgo Alonso Quijano, luego don Quijote.

Es muy probable que un hidalgo como Alonso Quijano mantuviera más de alguna formalidad propia de la nobleza; si no un escudo de armas, al menos un símbolo gráfico o título que lo identificase, a saber, una firma con la distintiva rúbrica nacida de su puño y letra. 
En este punto hay que hacer alguna precisión. Es bastante claro que la rúbrica, y no así la firma, estaba reservada para aquellos que sabían leer y escribir, los que en verdad no eran muchos, y que en todo caso pertenecían a las clases acomodadas. La clave está en que hay que entender por rúbrica una grafía singular, potencialmente sofisticada desde un punto de vista intelectual e incluso estético, puesto que con ella, formal y simbólicamente, se alude a una persona y a su condición. Digo esto porque la firma, en cuanto conjunto de grafías inteligibles que en su conjunto configuran un nombre, bien podía ser aprendida para efectos prácticos por alguien que no sabía leer ni escribir. De hecho, Sancho en dos oportunidades asegura que sabe firmar, y no hay razones de contexto que permitan suponer que no dice la verdad (II, XXXVI, p. 253 y II, XLII, p. 291).

En cuanto a don Quijote, él no sólo sabe leer: Es el prototipo del lector ideal del que se hablará, teóricamente, siglos más tarde. Su actitud frente a la fábula de los libros de caballerías es la de alguien que no conserva siquiera la mínima distancia espectador/espectáculo. Él es la mímesis victoriosa, llevada al extremo, la puesta en práctica de los relatos caballerescos insertos en un época remota, la edad de oro.

Ahora bien, cuando a don Quijote le toca escribir, el asunto adquiere un matiz distinto. En estas ocasiones (que no son muchas), lo que debe hacer el héroe es transformar un acto (el de escribir) en un instrumento válido para los esquemas de la andante caballería. El contenido de su operación textual, que inevitablemente es una acción presente, propia de Quijano, o sea, de la edad de hierro, debe responder a lo que se espera de un Amadís o de un Esplandián. El texto caballeresco requiere de las características de otro tiempo. Esto es precisamente lo que, con éxito, hace en la misiva a Dulcinea del Toboso, haciendo caso omiso de la conversación, recién sostenida con Sancho, en la que confesaba el carácter ficticio de su amada.

Esa carta escrita a Dulcinea no le impide a don Quijote resolver asuntos prácticos. Como se sabe, el cambio de nombre, el autobautizo de don Quijote, no trajo consigo el desconocimiento de sus circunstantes. Es decir, ama, sobrina, Pero Pérez, barbero, el mismo Sancho, siguieron siendo reconocibles para el nuevo caballero. Por lo mismo, y a menos que el cura decidiera transformar su imagen cual sabio encantador, la relación del héroe con ellos nunca perdió los supuestos cotidianos forjados en la época de Alonso Quijano. Es así como, al aceptar don Quijote entregar a Sancho los pollinos que le tenía prometido a modo de salario, don Quijote no duda en que éstos han de ser proveídos por Antonia Quijana, esto es, por la sobrina de Alonso Quijano. En dos palabras, la escisión de don Quijote no es tan radical como para no poder resolver las peticiones de aqui y de ahora que 
le hace su escudero, problemas inexistentes en los libros de caballerías y que tienen en la rúbrica y, más tarde, en el baciyelmo, sus máximas expresiones.

\subsection{La Q: Lo otro, también llamado "entre"}

Los lectores nunca tuvimos acceso a la rúbrica de don Quijote, mucho menos a la de Alonso Quijano. Pero sabemos que la estampó al pie de la carta destinada a la sobrina. Ante la necesidad de que los pollinos le sean entregados a Sancho y que, con ello, la identidad del caballero andante no se vea cuestionada, la rúbrica necesariamente ha de involucrar a don Quijote y a Quijano. ¿Qué símbolo o grafía sirve para uno y otro fin? Teniendo en cuenta las características señaladas que definían la rúbrica en tiempos de Cervantes, probablemente no haya mejor alternativa que una $Q$. Una $Q$ singular y personalísima, pero $Q$ al fin, en cuanto asociada tanto a un Alonso Quijano distante e inexistente, como al caballero andante de nombre don Quijote. Esa $Q$ es más que un resquicio leguleyo a un dilema puntual. Es más también que el punto de convergencia de dos entidades que, de pronto, deben funcionar al mismo tiempo: la que es poseedora de una pequeña estancia y algunos pollinos que sirven de sueldo, y la que persevera en su calidad de caballero andante y de penitente amoroso.

No es objeto de este trabajo sumergirse en la psykhé de don Quijote. Pero vale la pena aventurar que la escisión que sufre don Quijote, si es que la sufre, no corresponde a una, digamos, esquizofrenia severa. Su trastorno de personalidad, entendido como un yo dividido, no implica que el sujeto deje de percibirse como un todo integrado; las partes de don Quijote resuelven su conflicto de manera demasiado racional. La posible patología subyacente al actuar de nuestro héroe pronto queda cuestionada por una conciencia, por un yo que permite que el ideal se realice y se proyecte. En palabras de Edwin Williamson, "por debajo de la locura a veces parece haber cierto elemento de cálculo o interés personal ... el efecto general es el de desdibujar cualquier distinción clara entre el pensamiento lúcido y la acción demente del caballero" (1991, p. 210). Para Salvador Madariaga, en tanto, en la locura de don Quijote, "no muere del todo la razón, sino que parece dormir, y eso ligeramente, con intermitencias de lucidez que la hacen aflorar a veces a la superficie de la expresión" (1978, p. 107).

Estas intermitencias de lucidez no surgen al azar. Tampoco son producto de lo que más tarde Madariaga identifica como el "enemigo interior" del ideal caballeresco de don Quijote, enemigo que sería "el más formidable de cuantos combatió, el que acabó por vencerle y quitarle el gusto de vivir. 
Buena parte de su admirable energía se ha de gastar en esta lucha interna y silenciosa que a veces deja ver en momentos de turbación" (1978, p. 111). Si observamos con detenimiento el episodio ocurrido en Sierra Morena, no es la turbación el motivo de los lapsos racionales. La escisión responde a un orden más bien pacífico, no confrontacional, en el que el término medio, e incluso la solución misma, anteceden al conflicto. Es decir, gracias a marcas como la de la rúbrica, se explicitan de antemano, con elegancia y con la muy necesaria indeterminación quijotesca, dicotomías como la del cuerdo / loco (o racional / irracional, romántico / realista, etc.). Ese emblema estampado en el reverso del título y firma El Caballero de la Triste Figura, resume un tipo de simbiosis armónica entre los opuestos, hasta el punto de hacer intrascendentes estas categorías. Quiero decir que esa $Q$, y me refiero a esa $Q$ escrita en Sierra Morena, es la identidad reversible de don Quijote de la Mancha; su sensata ambigüedad; su ambivalencia (consciente / inconsciente, Alonso Quijano / don Quijote), su postura; su indeterminación y, por sobre todo, su atractivo.

\section{Conclusiones}

Don Diego Miranda, más conocido como el Caballero del Verde Gabán, es quien primero menciona la paradoja del cuerdo / loco, paradoja que ha sido una constante preocupación para la crítica sobre el Quijote ${ }^{19}$. Hay otras apreciaciones similares: "admirado quedó el canónigo de los concertados disparates, si disparates sufren concierto" (I, L, p. 447); “¿Es posible que hombre que sabe decir tales, tantas y tan buenas cosas ... diga que ha visto los disparates imposibles?" (Sancho, II, XXIV, p. 175); "es un loco cuerdo y un mentecato gracioso" (Sancho, II, XXXVI, p. 255). Aún más interesante es este intercambio de opiniones sobre don Quijote, entre don Diego y su hijo Lorenzo:

—No sé lo que te diga, hijo ... sólo te sabré decir que le he visto hacer cosas del mayor loco del mundo, y decir razones tan discretas, que borran y deshacen sus hechos ...

- No le sacarán del borrador de su locura cuantos médicos y buenos escribanos tiene el mundo [concluye más abajo Lorenzo]: él es un entreverado loco, lleno de lúcidos intervalos. (II, XVIII, pp. 125, 128.)

La paradoja del cuerdo / loco en el Quijote se basa, entre otros aspectos, en la alternancia de discursos y actos descabellados y absoluta-

${ }^{19}$ El Caballero del Verde Gabán dice que don Quijote "es un cuerdo-loco y un loco que tiraba a cuerdo" (II, XVII, p. 122). 
mente desapegados de la realidad verificable y aceptada por quienes lo rodean, y un razonamiento discreto, brillante incluso. Lo interesante es que esa paradoja la crea el personaje que la contiene y que, cosa notable, en caso de ser necesario, es resuelta salomónicamente por él mismo, sorprendiendo a quienes lo acompañan al interior de la diégesis e incluso a sus "autores" y lectores. Estos momentos de brillantez se dan en los escasos pero fundamentales "lúcidos intervalos" de los que habla Lorenzo. Es en ellos cuando los integrantes de la oposición contenida en la paradoja convergen en un mismo punto, hasta confundirse en un neologismo o, por qué no, en la síntesis que simboliza la rúbrica. Esto no deriva necesariamente en que la realidad percibida, sus antinomias o sus identidades en disputa, sean relativas en el Quijote. Por el contrario, ese tipo de neo-platonismo que manifiesta don Quijote en episodios clave como el del baciyelmo y, en particular, el de la firma y la rúbrica en Sierra Morena, bien puede entenderse como una manera de atestiguar que la verdad aparece como relativa simplemente porque es parcialmente comprensible (Moore, 1961, p. 661).

Según Foucault, don Quijote lee el mundo para demostrar los libros (1966, p. 61). Llevándolo al plano que imponen las soluciones baciyélmicas y la de la rúbrica, se podría reformular esta cita: don Quijote lee, transmuta y/o adapta el mundo en el que vive efectivamente para demostrar y, sobre todo, para actualizar los libros que lo han obsesionado. Lo cierto es que locura quijotesca no puede ser leída como un conjunto de actos gratuitos, ya que "esos actos aparecen arrancados de un contexto vivencial inmediato y desplazados a la esfera de la textualidad, donde las experiencias dependen menos del contexto existencial que del texto motivador (la 'fuente')" (Resina, 1989, p. 294). El hecho de que la locura de don Quijote esté cruzada por gestos y marcas que la suspenden, sin eliminarla, indica que ella es inevitable. Es la inevitabilidad de realizar la propia identidad, entendida ésta ahora como la suma total de la información que existe sobre don Quijote, con lo que el héroe termina confundiéndose con el texto que lo contiene (Riley, 1966, p. 128). La identidad de don Quijote, entonces, deja de ser un cúmulo de contradicciones — las que se alojan sólo en la personalidad-, y se convierte en un punto de convergencia al que perfectamente se puede aludir por intermedio de ese signo que escribe don Quijote en Sierra Morena, presumiblemente una $Q$ al pie de la carta a la sobrina.

Con marcas como la rúbrica se presagian asuntos que serán una constante en el Quijote de 1615: La quijotización de Sancho, un mayor grado de complejidad - si no inversión o invalidación - de los planos de realidad y de ficción, una creciente autorreflexión por parte de don Quijote 
$\mathrm{y}$, en especial, la definición por parte del héroe de su calidad intermedia o limítrofe: Entre la locura y la cordura, entre la historia y la literatura, entre el inasible Alonso Quijano el Bueno y don Quijote de la Mancha.

Dice el epitafio final compuesto por Sansón Carrasco:

Yace aquí el Hidalgo fuerte

Que a tanto extremo llegó

De valiente, que se advierte

Que la muerte no triunfó

De su vida con su muerte.

Tuvo a todo el mundo en poco;

Fue el espantajo y el coco

Del mundo, en tal coyuntura,

Que acreditó su ventura,

Morir cuerdo y vivir loco. (II, LXXIV, p. 490.)

Es burlesco el epitafio, no cabe duda. Pero incluso la burla lleva en sí su cuestionamiento, está marcada por su contrario. Paradójicamente, el "morir cuerdo y vivir loco" - idea que repite varias veces el propio don Quijote en su lecho de muerte (II, LXXIV, pp. 485-489) — parece sugerir que buena parte de la vida del hidalgo nunca fue hasta la venida del otro, ahora vuelto a llamar Alonso Quijano. Es como si éste, para adquirir materialidad e incluso fama, hubiera resuelto fundirse, y no reemplazarse, con el efímero caballero andante que "tuvo a todo el mundo en poco". Y cabe señalar que Alonso Quijano el Bueno, al hacer su testamento y entregarle a cada quien lo suyo, no niega haber sido un caballero andante: "fui don Quijote de la Mancha y soy, agora, como he dicho, Alonso Quijano el Bueno" (II, LXXIV, p. 489). Más bien, lo que ha dado por finalizado, bajo el lugar común de la locura, es la representación selectiva de la realidad y sus síntesis temporales y espaciales, simbolizadas por esa misteriosa rúbrica, hipotéticamente una $Q$.

\section{BiBLIOGRAFÍA}

Allen, John J.: Don Quixote: Hero or Fool? Gainesville: University Press of Florida, 1979.

Bal, Mieke: Teoría de la narrativa. Madrid: Cátedra, 1998.

Cervantes, Miguel de: El ingenioso hidalgo Don Quijote de la Mancha, edición de Joaquín Casalduero. Madrid: Alianza Editorial, 1984. 2 vols.

Corominas, Joan y Pascual, J. A.: Diccionario crítico etimológico castellano e hispánico. Madrid: Gredos, 1991. 2 vols. 
Covarrubias, Sebastián de: Tesoro de la lengua castellana o española, edición de Martín de Riquer. Barcelona: Ed. Alta Fulla, 1993.

Cruz, Anne J.: "Mirroring Others: A Lacanian Reading of the Letrados in Don Quixote". En: Ruth El Saffar. Quixotic Desire: Psychoanalytical Perspectives on Cervantes. Ithaca: Cornell UP, 1984. 93-116.

Durán, Manuel: La ambigüedad en el Quijote. México: Universidad Veracruzana, 1960.

El Saffar, Ruth (ed.): Quixotic Desire: Psychoanalytical Perspectives on Cervantes. Ithaca: Cornell UP, 1984.

Enciclopedia Universal Ilustrada. Bilbao: Espasa-Calpe, 1926. Vol. LII.

Foucault, Michel: Les mots et les choses: Une archéologie des sciences humaines. París: Gallimard, 1966.

Madariaga, Salvador: Guía del lector del Quijote (Ensayo psicológico sobre el Quijote). Madrid: Espasa-Calpe, 1978.

Moore, John A.: "Is Truth Relative for Cervantes?" Hispania, 44 (Dic. 1961): 660-662.

Real Academia Española: Diccionario de la lengua castellana, versión de Autoridades. Madrid: RAE, 1726-1739.

Real Academia Española: Diccionario de la lengua española, Vigésima Edición. Madrid: RAE, 1984

Resina, Joan Ramón: "Medusa en el laberinto: Locura y textualidad en el Quijote". MLN, 104 (Mar., 1989): 286-303.

Riley, E. C.: "Who's Who in Don Quixote? Or and Approach to the Problem of Identity". MLN, 81 (Mar., 1966): 113-130.

Riley, E. C.: Introducción al "Quijote". Barcelona: Crítica, 1990.

Weiger, John G.: The Individuated Self. Athens: Ohio UP, 1979.

Williamson, Edwin: El Quijote y los libros de caballerías. Madrid: Taurus, 1991. 